\title{
Rapid, single-step nucleic acid detection
}

\author{
Kyle A. Cissell • Sean Campbell • Sapna K. Deo
}

Published online: 9 September 2008

(C) Springer-Verlag 2008

Following publication, the authors have made an addition to the Acknowledgement section. It now reads:

Acknowledgement We would like to thank the National Science Foundation (CHE-0748648) for funding and the National Institutes of Health. S. Campbell would like to thank IUPUI National Science Foundation Louis-Stokes Alliance for Minority Participation for a fellowship.

The online version of the original article can be found at http://dx.doi. org/10.1007/s00216-008-2215-5.

K. A. Cissell $\cdot$ S. Campbell $\cdot$ S. K. Deo $(\triangle)$

Department of Chemistry and Chemical Biology,

Indiana University Purdue University Indianapolis,

402 N. Blackford St., Room LD 326,

Indianapolis, IN 46202, USA

e-mail: sdeo@iupui.edu 